\title{
Exogenous particles in lymph nodes in patients with shrinking pleuritis with atelectasis
}

\section{DERNEVIK}

From the Department of Thoracic and Cardiovascular Surgery, University of Göteborg, Sahlgrenska sjukhuset, Göteborg, Sweden

ABSTRACT Shrinking pleuritis with atelectasis is a disease in which a compression atelectasis of the lung is caused by shrinking of the inflamed visceral pleura. This reaction has been attributed to asbestos. By means of scanning electron microscopy, with computerised $x$ ray spectrophotometry and $x$ ray diffraction analysis, tissue samples from the lymph nodes of patients with the disease and control subjects were examined for other particles of possible aetiological importance. The results would suggest, however, that asbestos is the most important factor in the aetiology of shrinking pleuritis with atelectasis.

Shrinking pleuritis with atelectasis is characterised by a localised, ball shaped area of pulmonary atelectasis trapped under a contracted visceral pleura. Radiologically it may be confused with a pulmonary tumour. ${ }^{1}$ The radiological features have been described frequently in the last few years, but there are few surgical series. We have reported a series of 28 patients collected during the years 1970-80, most of whom had been exposed to asbestos and had parietal pleural plaques. ${ }^{2}$ The finding of a history of asbestos exposure in these patients is consistent with other recent reports. ${ }^{3}$

At operation the lesion consists of an area of atelectasis in the lung, with a dense coating of fibrous tissue in the pleura. When this tissue is peeled off, the underlying lung expands and resumes its normal appearance. In seven of our patients a lung biopsy specimen was taken at operation. Asbestos bodies were present in four of these samples. Much carbon pigment and probable silica particles were also found, both under the pleura and in the parenchyma.

Although asbestos seems to be the most likely extrinsic aetiological factor, other particles, not easily seen by light microscopy, could be important. The aim of this study was to investigate the possible role of such particles in patients with shrinking pleuritis with atelectasis and all available mediastinal lymph node samples from the above mentioned series of patients were examined by light microscopy, by electron

Address for reprint requests: Dr L Dernevik, Department of Thoracic and Cardiovascular Surgery, Sahlgrenska sjukhuset, S-413 45 Göteborg, Sweden.

Accepted 22 April 1985 microscopy with electron probe microanalysis with $\overrightarrow{0}$ energy dispersive spectrometry, and by $x$ ray diffraction analysis.

\section{Patients and methods}

Formaldehyde fixed lymph node specimens embedded in paraffin were available for 12 patients who had previously undergone surgery for shrinking pleuritis with atelectasis. All were smokers and all had had mediastinoscopy as part of the routine investigation for a suspected pulmonary tumour. For every patient a control subject was selected from the same tumour screening protocol. The patients (group 1) and controls (group 2) were matched with regard to sex, age, and smoking habit (table 1). The control patients had limited lung carcinomas without invasion of the lymph nodes subjected to biopsy.

All lymph node specimens were examined with light microscopy with and without polarized light.

For scanning electron microscopy slices of the

Table 1 The two groups of patients from which lymph node specimens were available for examination by light microscopy

\begin{tabular}{|c|c|c|}
\hline & \multicolumn{2}{|l|}{ Group } \\
\hline & $S P A(n=12)$ & $\mathrm{Ca}(n=12)$ \\
\hline $\begin{array}{l}\text { Mean (SD) age }(y) \\
\text { Male:female }\end{array}$ & $\begin{array}{l}60(3.2) \\
11: 1\end{array}$ & $\begin{array}{l}60(2.7) \\
11: 1\end{array}$ \\
\hline $\begin{array}{l}\text { No of smokers and } \\
\text { ex-smokers* }\end{array}$ & 10 & 10 \\
\hline
\end{tabular}


samples, $15 \mu \mathrm{m}$ thick, were mounted on acrylic plastic and coated with a layer of carbon $300 \AA$ thick. The microscope used was a Jeol JSM-35 (Tokyo). The surface of the samples was first searched with a back scatter detecter to find areas with an atomic weight above the mean weight of the biological material. Any particles found by this method were analysed further with an electron probe microanalyser and energy dispersive spectrometer (EDS, Edax-711, Chicago). With this equipment analysis of the elements of every particle could be performed. ${ }^{4-7}$

Attempts were made to assess further the nature of the particles by $x$ ray diffraction analysis with a Guinier camera (XDC-700, Incentive Research Development, Stockholm). Small chips of the sample were put on a glass rod and rotated slowly while being irradiated by an $x$ ray beam with a wavelength of $1.5418 \AA$ for two to four hours. The resulting distances between the absorption bands and a reference spot were measured in a low power microscope and registered to allow computerised comparisons with about 10000 reference samples. $^{8}$

\section{Results}

\section{LIGHT MICROSCOPY}

Asbestos bodies were seen in five of the lymph node preparations from patients with shrinking pleuritis with atelectasis but in none of those from the controls.

\section{ELECTRON MICROSCOPY}

Back scatter imaging and $x$ ray mapping for silicon showed aggregates of material containing silicon both in the patients with shrinking pleuritis with atelectasis and in the controls (fig 1 ). The $x$ ray spectrum tech-

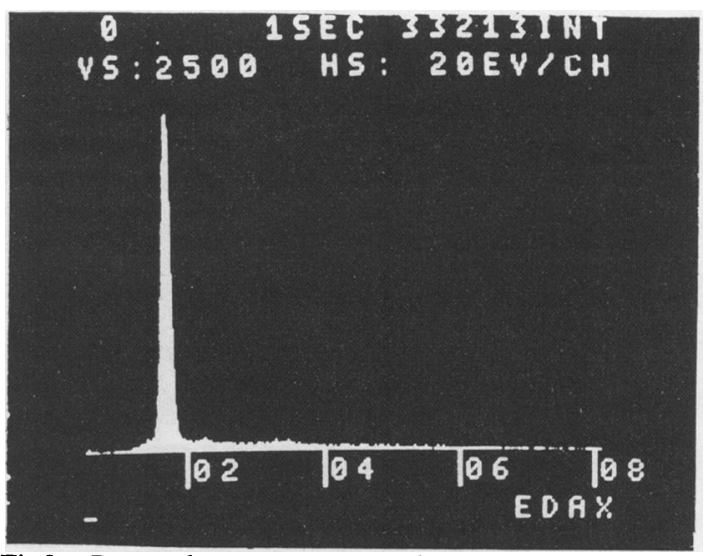

Fig 2 Energy dispersive spectrum from a particle in a lymph node sample with a single peak in the position for silicon. This is interpreted as evidence for silicon dioxide because silicon does not occur in free forms and oxygen is not demonstrated by the energy dispersive spectrum.

nique showed further particles containing pure silicon dioxide (fig 2) or silicon in conjunction with other elements (fig 3 ). There were also areas with particles of phosphorus and sulphur in combination.

Pure silicon dioxide particles were present in seven of the samples in the study group and in two of these there was a high concentration. In six control patients pure silica particles were found, with a high concentration in one. Silicon in composite particles containing aluminium, potassium, iron, and titanium was found in three of the study group and in 11 of the controls.
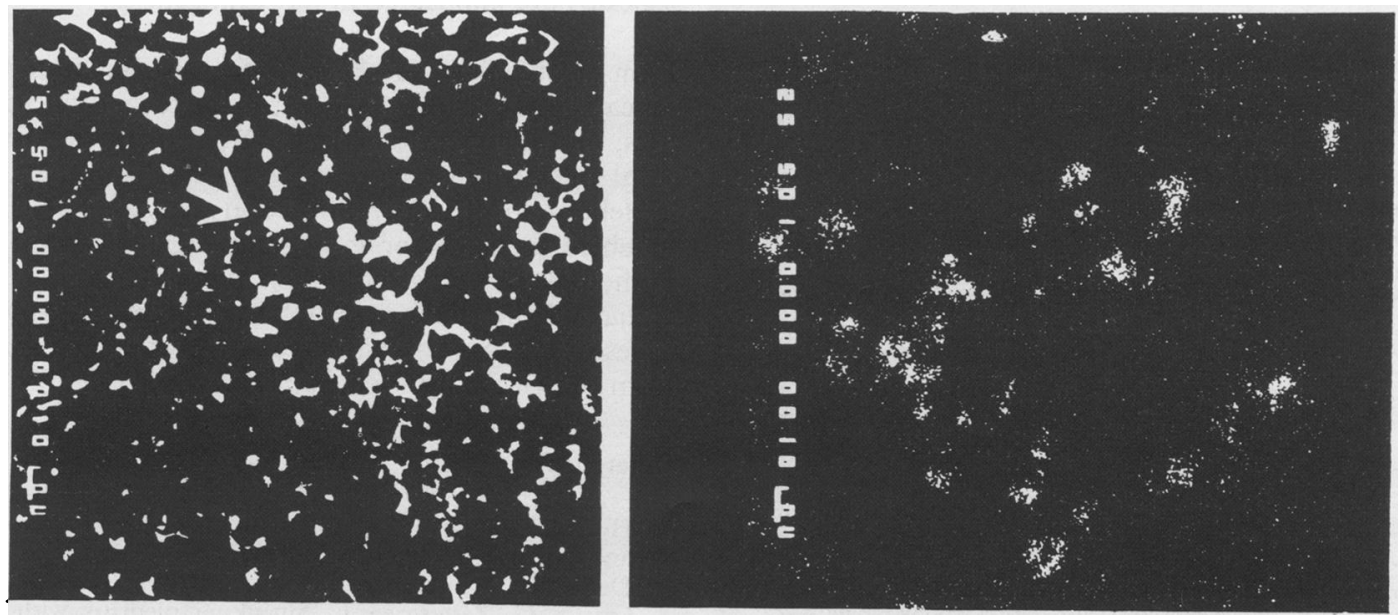

Fig 1 (a) Backscatter and (b) $x$ ray map for silicon of a lymph node sample. White areas in the backscatter picture (arrow) contain atoms of higher atomic number than the average for biological material, in (b) the concentrations of white dots represent silicon atoms from the same areas as in (a). 


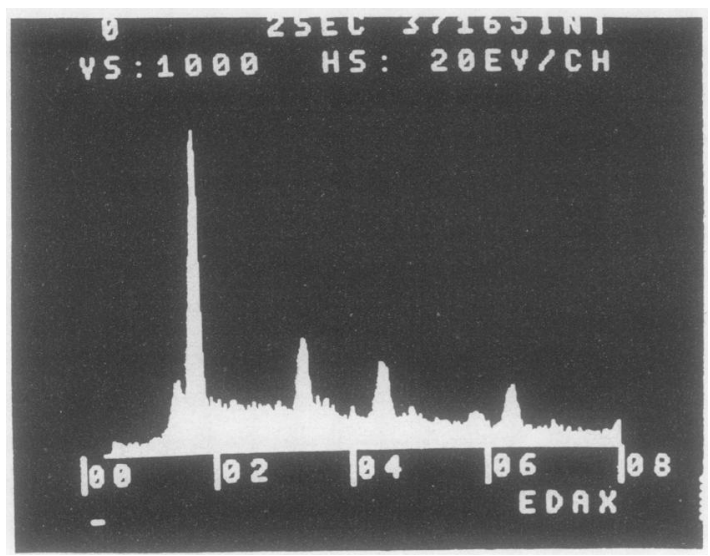

Fig 3 Energy dispersive spectrum from a particle in a lymph node sample with peaks in the positions for aluminium, silicon (high peak), potassium, titanium, manganese, and iron (from left to right).

\section{RAY DIFFRACTION ANALYSIS}

The analyses with the electron microscope showed no differences between the two groups, and therefore only the particles from patients with shrinking pleuritis with atelectasis were analysed further. The analyses confirmed the presence of silica as demonstrated by the electron microscopic techniques. Attempts to identify the molecules in the composite particles, however, gave no definite result; but some compounds can be considered as probable components of the particles (table 2). All these compounds are minerals.

\section{Discussion}

Asbestos, silica, ${ }^{1-39}$ blunt thoracic trauma, ${ }^{10}$ mitral disease, ${ }^{9}$ and postmyocardial infarction syndrome ${ }^{11}$ have all been implicated in the pathogenesis of shrinking pleuritis with atelectasis. In two studies a high incidence of asbestos exposure has been

Table 2 Probable occurrence of materials in lymph node samples from patients with shrinking pleuritis with atelectasis

\begin{tabular}{|c|c|c|}
\hline $\begin{array}{l}P D F \\
N o \dagger\end{array}$ & Formula & Name \\
\hline $\begin{array}{l}11-0222 \\
18-0991\end{array}$ & $\underset{\mathrm{K}_{4} \mathrm{Al}_{2} \mathrm{Si}_{2} \mathrm{O}_{9}}{\mathrm{NaALSO}}$ & \multirow{2}{*}{$\begin{array}{l}\text { carnegieit } \\
\text { potassium aluminium } \\
\text { silicate } \\
\text { calcium silicate } \\
\text { ilmenit } \\
\text { sodium aluminium } \\
\text { silicate }\end{array}$} \\
\hline $\begin{array}{l}24-0234 \\
29-0733 \\
30-1148\end{array}$ & $\begin{array}{l}\mathrm{Ca}_{2} \mathrm{SiO}_{4} \\
\mathrm{FeTiO}_{3} \\
\mathrm{Na}_{2} \mathrm{OAl}_{2} \mathrm{O}_{3} \mathrm{SiO}_{2}\end{array}$ & \\
\hline
\end{tabular}

*In most cases the $x$ ray diffractogram allowed different interpretations. The substances listed were among the most probable constituents in at least five of the patients. †Assigned by Joint Committee of Powder Diffraction Standards, Pennsylvania.

PDF-powder diffraction file. reported-nine out of 10 patients and nine out of 12 ज्ञ patients respectively. ${ }^{12}$ In our experience most $\overline{0}$ patients had either been exposed to asbestos or had $\bar{C}$ pleural plaques or both, which suggests that asbestos is a major aetiological factor. The presence of asbestos bodies in lymph nodes and lung biopsy specimens lends further support to this theory. ${ }^{2}$ The absence of asbestos bodies in some patients does not rule out asbestos exposure, since for every asbestos body there may be hundreds of asbestos fibres that are undetectable by light microscopy. ${ }^{1213}$

Many patients are exposed to asbestos but few develop shrinking pleuritis with atelectasis, and it therefore seemed possible that other substances, $\vec{N}$ perhaps acting in combination with asbestos, were 6 responsible. Few patients reported exposure to $\infty$ quartz, textile fibres, glass fibre, or chemicals, but there appeared to be large numbers of quartz particles in the lymph nodes. For this reason, electron microscopic and $x$ ray diffraction studies were undertaken.

The presence of quartz was confirmed, and compound particles containing silicon and other elements were also found. But the concentrations of $\vec{\theta}$ these materials were not different in the study group os and the control patients, indicating that there were no external factors other than asbestos and possibly smoking in the aetiology of shrinking pleuritis with atelectasis. It is more likely that individual susceptibility plays a part; interestingly, immunological investigation of a group of patients with the disease showed a deficiency in T cell function. ${ }^{14}$

Shrinking pleuritis with atelectasis would seem to be a special variety of asbestos related fibrotic change, occurring in patients who smoke and have defective $T$ cells. There is no evidence that minerals other than asbestos are implicated in its pathogenesis.

I am indebted to Lars Eklund, Swedish Institute for Silicate Research, for the electron microscopical analyses; and Gunnar Rehnberg, Department of Structural Chemistry, Faculty of Medicine, University of Göteborg, for the $x$ ray diffraction analyses. I am also 의 indebted to Professor L Zettergren, Department of $\rightarrow$ Pathology II, Sahlgrenska sjukhuset, Göteborg, for valuable aid with the detection by light microscopy of $N$ asbestos bodies. This work was supported by a grant from the Göteborg Medical Society.

\section{References}

1 Hillerdahl G, Hemmingsson. Pulmonary pseudotumours and asbestos. Acta Radiol 1980;21:615-20.

2 Dernevik L, Gatzinsky P, Hultman E, Selin K, WilliamOlsson G, Zettergren L. Shrinking pleuritis with at- Ō electasis. Thorax 1982;37:252-8.

3 Tylén U, Nilsson U. Computed tomography in pul- $\frac{\curvearrowright}{\mathbb{D}}$ monary pseudotumours and their relation to asbestos 
exposure. Journal of Computer Assisted Tomography 1982;6:229-37.

4 Yakowitz H, Goldstein JI. Practical aspects of $x$ ray microanalysis. In: Goldstein JI, Yakowitz H, eds. Practical scanning electron microscopy. New York: Plenum Press, 1975:401-17.

5 Gaudichet A, Dumortier P, Jedwab J, Jernault JC. Mineralogical analysis of bronchoalveolar lavage fluid as an aid to diagnosis of "imported" pleural asbestosis. Thorax 1983;38:628-9.

6 Goldstein JI. Electron beam-specimen interaction. In: Goldstein JI, Yakowitz H, eds. Practical scanning electron microscopy. London: Plenum Press, 1975:49-94.

7 Hayes TL. Characteristic $x$ ray elemental analysis: In: Koeler JK, ed. Advanced techniques in biological electron microscopy. Berlin: Springer-Verlag, 1973:196.

8 Rüttner JR, Spycher MA, Sticher H. The detection of etiologic agents in interstitial pulmonary fibrosis. Hum Pathol 1973;4:497-512.
9 Brune J, Bosly A, Bory R, Perinetti M, Wiesendanger T, Galy $\mathbf{R}$. Condensations parenchymateuses pulmonaires arrondies post-pleuretiques. Mecanisme physiopathologique. Lyon Médical 1974;231:605-9.

10 Cho SR, Henry DA, Beachley MC, Brooks JW. Round (helical) atelectasis. Br J Radiol 1981;54:643-50.

11 Schneider HJ, Felson B, Gonzales LL. Rounded atelectasis. $A J R$ 1980;134:225-32.

12 Hillerdahl $\mathrm{G}$. The pathogenesis of pleural plaques and pulmonary asbestosis: possibilities and impossibilities. Eur J Respir Dis 1980;61:129-38.

13 Jones JSP. Pathology and experimental pathology of asbestos dust exposure. In: Michaels L, Chissik SS, eds. Asbestos. Vol 1: Properties, applications and hazards. Chichester: John Wiley and Sons, 1979:715-6.

14 Dernevik L, Björkander J, Hansson L- $\AA$, Larsson S, Söderström T, William-Olsson G. Immunological abnormalities in shrinking pleuritis with atelectasis. Eur $J \mathbf{R e}$ spir Dis 1985;66:728-34. 